\title{
Living Predicament and Improvement Strategies of 0-3 Year-Old Children Early-Education Teachers in Chongqing
}

\author{
Dan $\mathrm{Li}^{1, \mathrm{a}^{*}}$ \\ ${ }^{1}$ Preschool Education College, Chongqing University of Education, 400067 Chongqing, China \\ alidan@cque.edu.cn
}

Keywords: 0-3 year-old children education; Early-education teacher; Career state.

\begin{abstract}
The living state of 0-3 year-old children early-education teachers directly determines the quality of early-education and healthy development of early-education career of a nation. To get to know the living state of 0-3 year-old children early-education teachers in Chongqing, China, this study selected 136 early-education teachers in this city by stratified sampling. They were asked to fill in a questionnaire to evaluate their career state and eighteen of them were individually interviewed for detailed information. The results showed that the salary of early-education teachers is generally low while job stress and burden are relatively high. They lack the effective support for their professional development and have strong sense of job burnout. The data also showed high career mobility among the early-education teachers. Therefore, improving the living state of early-education teachers deserves great attention from the education administrative department and early-education organizations. Proposed strategies include improving their welfare, creating a harmonious working environment, strengthening their professional capacity training and reducing their work burden, etc.
\end{abstract}

\section{Introduction}

0-3 year-old children early-education is the beginning stage of our national lifelong education system, so it plays an important role in laying the foundation for the beginning of our life. With the continuous improvement of national income and the increasing awareness of the importance of early-education, early-education organizations dedicated to the development of 0-3 year-old children and family education guidance have mushroomed across the country in recent years. The National Program of Action for Child Development in China (2001 -2010) approved by the State Council in 2001 presents the idea of "developing 0-3 year-old children early-education for the first time. National outline for Medium and Long-term Education Reform and Development (2010-2020) also clearly points out "attaching importance to 0-3 year-old children education". During the development boom of early-education, the number of early-education teachers also increases exponentially. As a new-emerging group of teachers, their living state is not only related to their own professional development and life quality, but also directly determines the quality of early-education and the healthy development of early-education career in the country.

"Living state refers to the various life forms that people show in the daily material and spiritual environment and in the specific historical and cultural background"[1]. In order to investigate study and deeply analyze the teachers' living state and the connotation of their living state, their living state will be divided into several observable specific dimensions. Take the study of preschool teachers' living conditions for example, some researchers believe that analysis of preschool teachers' living conditions should include "economic income, life quality, working conditions, professional ability and development opportunities, occupational reputation and social status, interpersonal relationship and social care, social support and security, development expectation and prospects and so on"[2]. Some researchers thoroughly analyse the living state from "salary, working environment, job stress, professional development and subjective happiness"[3]. Besides, other researchers simply divide the living state of teachers into the following aspects: salary, work pressure, social status and continuing education"[4]. In addition, studies have proved that "personal background characteristics can greatly influence his/her job satisfaction, while the level of children' development is often related to the personal background of teachers to a certain degree"[5]. Based on the above research results, this 
study will discuss the living state of early-education teachers from the aspects of personal background, salary, work pressure, professional development and work load.

\section{Objects and Methods}

This study used the self-made Early-education Teachers' Living Condition and Professional Development Questionnaire and adopted stratified random sampling method to make a survey on early-education institution teachers in nine areas of downtown Chongqing. Eighteen early-education institutions were selected (Jiangbei District 3, Yubei District 1, Beibei District 1, Yuzhong District 2, Jiulongpo District 2, Shapingba District 2, Dadukou District 2, Nan'an District 3, Banan District 2) and a total of 150 early-education teachers were selected as the research objects. In the end, we got 136 effective questionnaires and the effective rate was $91 \%$. Then, we chose 18 early-education teachers from 3 early-education institutions for individual in-depth interviews in order to further understand the living state of early-education teachers. Their information was used as the supplement for the data collected from the questionnaires, so that the researcher can make a more realistic description and analysis.

\section{Results and Discussion}

The living state and development hindrance of early-education teachers.

Young background of early-education teachers. In order to understand the living and development background of early-education teachers, this study did a survey about their age, working years and other basic personal background. The specific results are shown in Table 1 and Table 2.

Table 1 Age distribution of early-education teacher

\begin{tabular}{ccc}
\hline Ages & Number of People & Percentage \\
\hline under 20 & 8 & $5.88 \%$ \\
from 21 to 35 & 52 & $38.24 \%$ \\
from 26 to 30 & 68 & $50.00 \%$ \\
over 30 & 8 & $5.88 \%$ \\
sum & 136 & $100.00 \%$ \\
\hline
\end{tabular}

Table 2 Years of working in early-education career

\begin{tabular}{ccc}
\hline Working years & Number of People & Percentage \\
\hline less than 1 year & 20 & $14.71 \%$ \\
from 1 to 5 years & 96 & $70.59 \%$ \\
from 6 to 10 years & 16 & $11.76 \%$ \\
more than 10 years & 4 & $2.94 \%$ \\
sum & 136 & $100.00 \%$ \\
\hline
\end{tabular}

Among the 136 early-education teachers, age from 26 to 30 accounts for $50 \%$, which is the highest, and under 30 accounts for $94.12 \%$. At the same time, working years within 5 years accounts for $70.59 \%$ and working years under 10 years accounts for $97.06 \%$. It can be seen that the age of early-education teachers is generally young, and most of them have a short working life and lack of work experience, which may lead to high mobility and more new teachers in this area. Moreover, most of these young and inexperienced early-education teachers are unmarried and childless, so they lack direct birth experience. Without solid professional knowledge and cultivation, their education guidance for parents is vulnerable to be doubted.

Low salary of early-education teachers. Salary is the material foundation for laborers' basic life. Marx's labor value theory points out that "the connotation of free and all-round development of human beings includes safe working conditions, reasonable income, reliable social security and dignified work"[6]. Salary is the most important source of the basic life of early-education teachers. 
Only when their salary is guaranteed to a certain extent can the teachers put greatest enthusiasm into the early-education teaching activities and pay attention to the development of infants and the needs of family education. The data obtained from the questionnaire here is the actual salary of early-education teachers after deducting five kinds of social insurances and housing accumulation fund every month and without other benefits.

Table 3 Monthly salary of early-education teachers

\begin{tabular}{ccc}
\hline Monthly Salary & Number of People & Percentage \\
\hline below CNY 2000 & 16 & $11.76 \%$ \\
CNY 2000-3000 & 44 & $32.35 \%$ \\
CNY 3000-4000 & 60 & $44.12 \%$ \\
higer than CNY 4000 & 16 & $11.76 \%$ \\
\hline
\end{tabular}

From Table3, we can see that $76.47 \%$ of early-education teachers are paid between 2,000 and 4,000 yuan, and only $11.76 \%$ of early-education teachers get paid higher than the average monthly salary of Chongqing (3,995 yuan) calculated by China Daily in 2014. The following table shows the early-education teachers' satisfaction toward their salary.

In fact, the requirements for early-education teachers are very high, which not only shows in teaching quality, but also in work experience and personal qualities of teachers. The deviation between high demands and low income results in many early-education teachers' dissatisfaction to their salary, but the dissatisfaction is not expressed clearly. It can be known from Figure 1 that the data of satisfied and very satisfied account for about 30\%, dissatisfied and very dissatisfied account for about $20 \%$, while unknown accounts for $47.06 \%$. This is because most early-education institutions are private enterprises. They charge high fees, have large expenses and are responsible for their own profits and losses. So they have to control operating costs and save salary expenses so as to maximize profits.

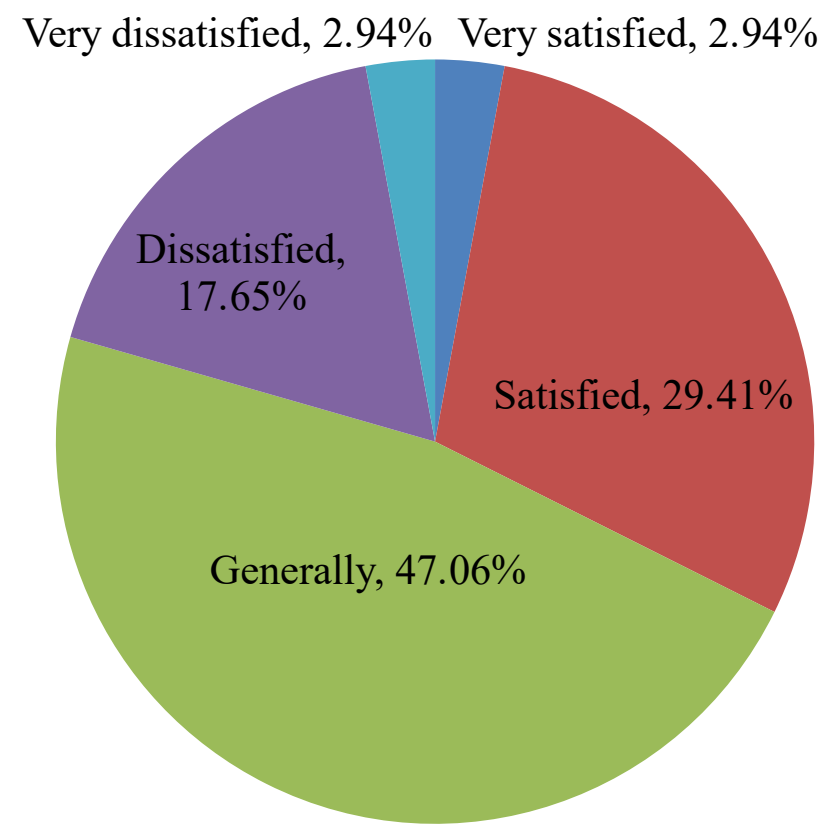

Figure. 1 Salary satisfaction of early-education teachers

High work pressure of early-education teachers. Work pressure refers to the stress on one person caused by excessive workload, changing production position or overweight responsibilities and changes. Work pressure affects teachers' satisfaction to their living conditions. "Moderate work stress can inspire potential, but excessive work stress can easily cause physical and psychological problems, thus reducing work efficiency"[7]. According to the questionnaire, early-education teachers are 
generally under high pressure, with $14.74 \%$ very stressed, $64.71 \%$ stressed, $20.59 \%$ a little stressed, and $0 \%$ unstressed.

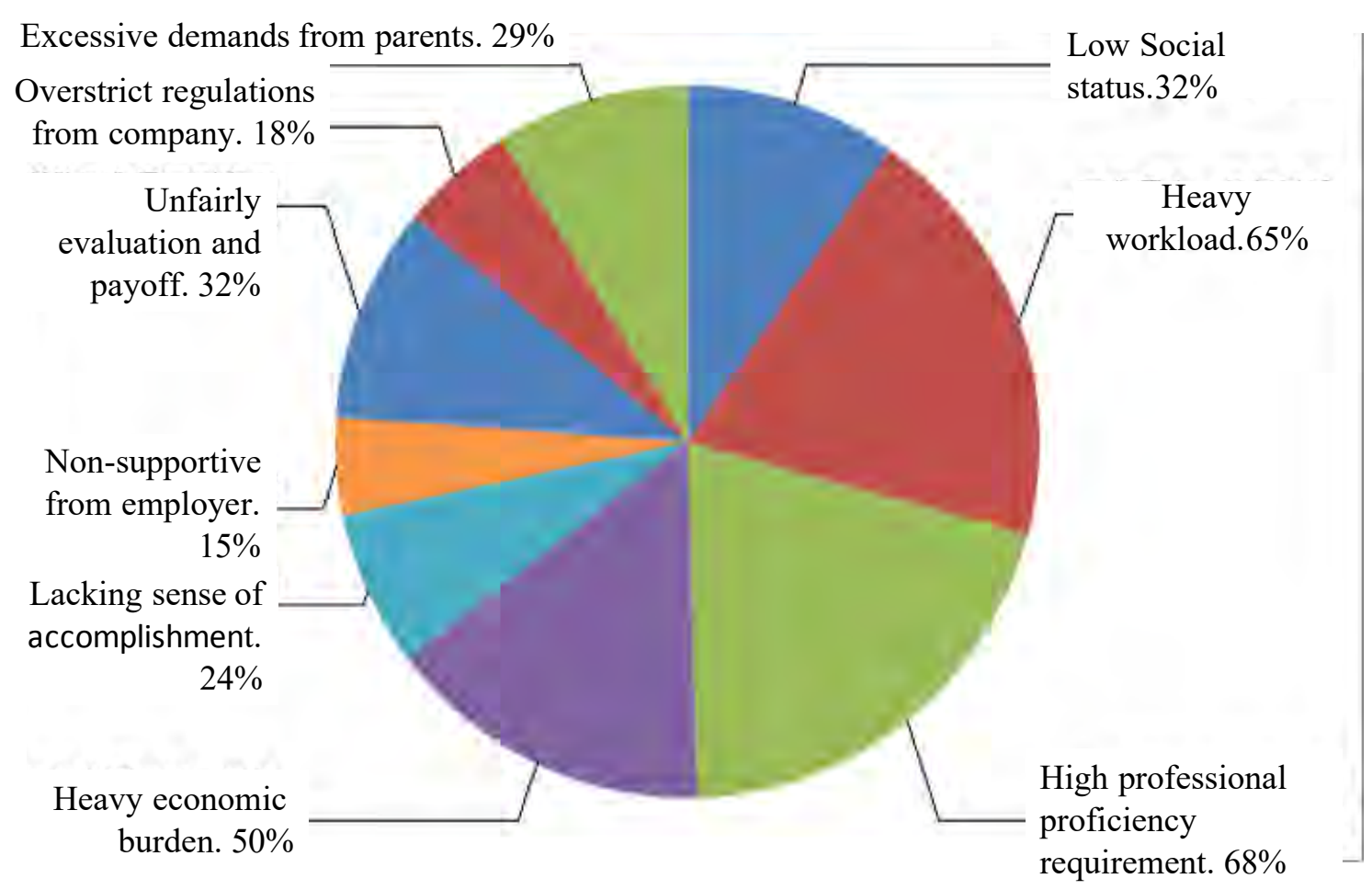

Figure 2. Pressure-bearing of early-education teachers

As can be seen from Figure 2, most early-education teachers believe that the pressure come from heavy workload, heavy burden and higher requirements for teachers' professional abilities, all of which have exceeded $60 \%$, while low salary and heavy financial burden also account for $50 \%$. At the same time, low social status and pressure from parents and leaders are also main sources of their pressure. The root of these pressures is that the private early-education institutions are usually run as companies, with strict regulations, distinct rewards and punishments. As a result, teachers there are not allowed to make mistakes and the relationships with colleagues are highly competitive.

Nonsupport for professional development of early-education teachers. As shown in Table 4, 58.82\% surveyed early-education teachers have bachelor's degree and $61.76 \%$ major in pre-school education. So their educational level is not very low and they have received teaching training mainly in pre-school education aspect. However, as pre-school education major courses in normal school are mainly offered for children aged 3-6 years and there are few professional courses for children aged 0-3 years, the students lack professional training for early-education of children aged 0-3 years. The younger the infants are, the greater development differences between ages are shown. So the teaching theories and practicing experiences for children aged 3-6 years cannot be fully migrated to the education for children aged 0-3 years. Therefore, most early-education teachers should receive special early-education training to become qualified for early-education work even if they have professional learning background of pre-school education. However, because of the shortage of teachers for early-education institutions, many early-education teachers rush to work without systematic early-education training, which seriously affects the teaching quality. 
Table 4 Education backgraound of early-education teachers

\begin{tabular}{ccc}
\hline Final Degree & Number of People & Percentage \\
\hline technical secondary school or high school & 20 & $14.71 \%$ \\
junior college & 36 & $26.47 \%$ \\
bachelor & 80 & $58.82 \%$ \\
master and higher & 0 & $0.00 \%$ \\
sum & 136 & $100.00 \%$ \\
\hline
\end{tabular}

Table 5 Specialties of early-education teachers

\begin{tabular}{ccc}
\hline Major & Number of People & Percentage \\
\hline preschool education or early-childhood education & 84 & $61.76 \%$ \\
other majors for teachers' education & 48 & $35.29 \%$ \\
non-educational majors & 4 & $2.94 \%$ \\
sum & 136 & $100.00 \%$ \\
\hline
\end{tabular}

Early-education is a highly-professional job, so early-education teachers have to insist on lifelong learning in order to constantly improve the quality of early-education. However, early-education teachers have very limited opportunities to participate in in-service learning and lack a lifelong learning platform. As shown in Table 5, the early-education teachers who participate in annual advanced training account for $74.47 \%$ while $23.53 \%$ of early-education teachers do not attend any further training. And those who participate more than 3 times every year account for only $23.08 \%$. The number of on-the-job training is few and the time is short, so this kind of training has extremely limited value on the professional development of early-education teachers.

Heavy burden of early-education teachers. Work load refers to the work that human body bears in unit time, including manual workload and mental workload. According to the questionnaire, the number of people whose daily workload is less than 8 hours is 20 , which accounts for $14.71 \%$. Most people work between 8-10 hours, with 112 people accounting for $82.35 \%$. Only 4 people work more than 10 hours, accounting for $2.94 \%$.

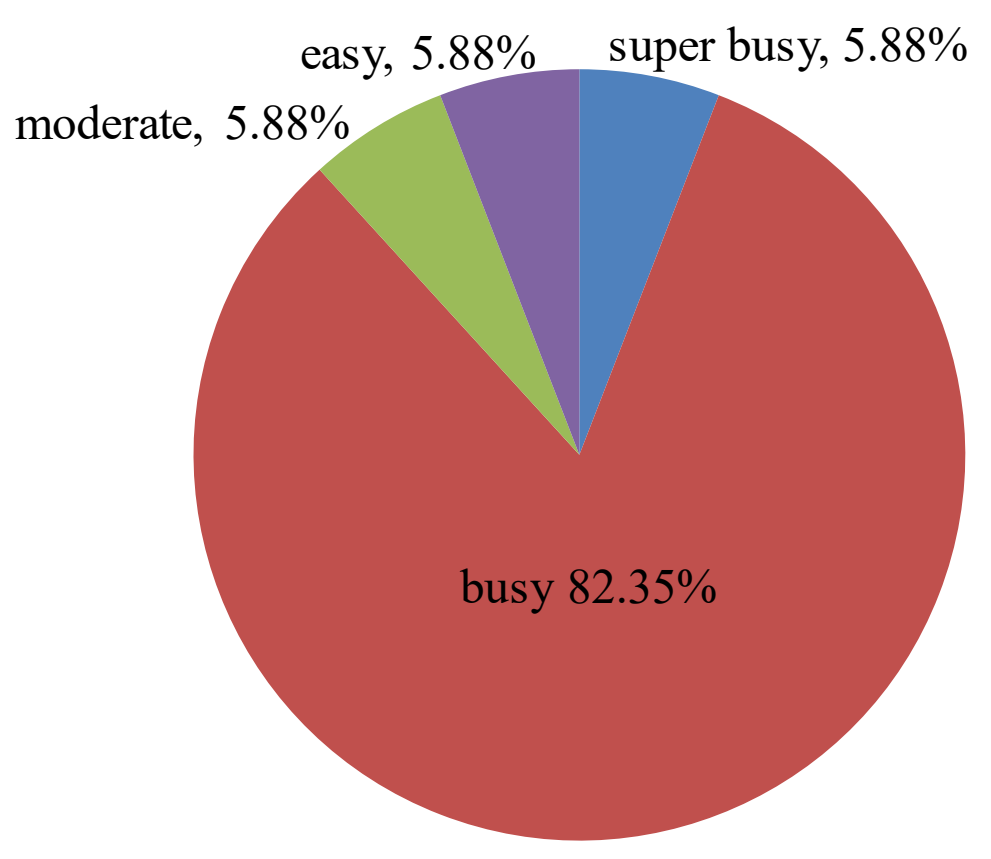

Figure 3 Self-assessment of early-education teachers' workload 
According to Figure 3, most early-education teachers feel that their workload is relatively large and their work is busy. The legal working time stipulated by the state is 8 hours, but most early-education teachers have already exceeded this regulation, so the workload of early-education teachers exceeds the standard compared with other jobs. Studies have shown that "The larger the workload is, the lower their satisfaction to their living state is" [8]. "Whether their living state is good or bad depends on whether the problems of their living conditions and pressures are solved"[9]. It can be inferred that the satisfaction of early-education teachers to their living state will be affected by heavy work and fall to the bottom.

The main reason for this situation is the improper management of early-education institutions. First of all, the mobility of early-education teachers is very high, resulting in shortage of staff in short time, so many early-education teachers usually have to complete more work. Secondly, the management of early-education institutions is chaotic and the work responsibility is not clear. After completing the teaching tasks, early-education teachers have to frequently participate in various meetings, plan and arrange large-scale activities. In addition, in order to emphasis on their features, some early-education institutions develop school-based curriculum, which costs lots of time and energy of early-education teachers to develop and prepare these courses. Faced with increased workload, early-education teachers have to sacrifice their break time to finish their work, so their working enthusiasm decreases linearly.

\section{Strategies to develop early-education teachers' living state.}

Improve management mechanism of early-education institutes and increase the salary of early-education teachers. In order to stabilize the team of early-education teachers and improve the overall quality of the early-education teachers, the country should first increase the investment in the early-education career, strengthen the management of early-education institutions and promote public early-education institutions. "Due to the particularity of objects' age, early-education for infants aged 0-3 years, as an education career, should clearly definite the responsibility subjects. The city and county (district) governments should organize and instruct the Bureau of Education to take the main responsibility. And the Bureau of Education should cooperate with the Family-planning Department, the Health Department and the Women's Federation to form the joint efforts of management" [10]. At the same time, all government departments should jointly issue relevant laws, regulations and policies to improve the management system of early-education institutions, achieve the standardized and stereotyped management of early-education institutions and further improve the security mechanism related to the salary of early-education teachers, increasing the income of early-education teachers and protecting their legitimate rights and interests. Because the status and salary of teachers are closely related to the vital interests of teachers, they have a significant impact on the growth of teachers and the attraction of this career. Only by constantly improving the working and living conditions of early-education teachers can excellent talents be attracted to work in early-education for a long time, or even for a lifetime.

Create a harmonious work environment and prompt to learn pressure management. "People who work under high pressure for a long time are prone to show burnout. As early-education teachers, once they show burnout, it will cause a great harm"[11]. Early-education institutions should pay more attention to their employees' occupational stress, create loose, democratic and harmonious working environment and reduce the source of stress and anxiety, which keeps the teachers continuous work motivation and enough enthusiasm. The institutes can organize some psychological consultation activities on relieving pressure and offer a variety of skills to cope with pressure, such as physical exercise, talk, cultivating business hobbies and so on to improve early-education teachers' compressive abilities, correct their attitude toward pressure, learn to manage stress and relieve the tense work atmosphere.

Strengthen career capacity training and pay attention to the professional growth of early-education teachers. As an important human resource, the professional level of early-education teachers is not only related to personal growth, but also an important way to improve the overall quality of early-education institutions. Early-education institutions should pay attention to the professional growth of their teachers, invite experts to make academic lectures, actively organize 
their teachers to study abroad or participate in continuing education and encourage communication to absorb others' excellent teaching experience and constantly consolidate their own professional knowledge. In addition, the government should also provide lifelong learning resources for early-education teachers, organize professional training and research activities of early-education, and "perfect the overall planning and management on early-education of the related national departments, give full play to the government's leading role, create a better development platform and opportunity for early-education of infants. The government should also establish the overall planning and management system of early-education to enable them to conduct various studies in a planned and purposeful way"[12]. In this way, the professional development of early-education teachers will become more comprehensive, scientific and theoretical-based and can also get more practical guidance.

Reduce work burden of early-education teachers and improve their work efficiency. Heavy workload reduces the work happiness index of early-education teachers, so the improvement of early-education teachers' living state should start with the reduction of workload, both external reduction of workload and internal improvement of work abilities. To be specific, early-education institutions should first improve their teacher team and ensure the demand for operation, so that each teacher's workload is within the standard workload stipulated by our country and at the same time, increase the number of logistics staff, so that teachers can concentrate on early-education activities. Secondly, early-education teachers' work efficiency is inversely proportional to their workload. Only through early-education teachers' reasonable and efficient arrangement of work time and work progress in a planned way can they make the maximum value within limited energy, improve their work ability and master their teaching skills. Finally, it is necessary to straighten out the interpersonal relationships at work and properly handle the relationships with managers, colleagues, parents, etc. so as to reduce the resistance in work and improve work efficiency.

\section{Summary}

Therefore, in order to improve the quality of early-education for children aged 0-3 years, we should pay close attention to the living state of early-education teachers. It is of critical importance that the early-education teachers are in a good physical and mental state, lead a successful career and have excellent professional capacity, so that they can bring the society with high-quality education to $0-3$ year old children and guidance to their parents.

\section{Acknowledgements}

This work is part of the achievements of Chongqing 13th Five-Year plan for educational research project,"research on the promotion mechanism of service capability of inclusive private kindergartens in Chongqing from the perspective of education equity"(2017-GX-033), and Sichuan key research base of humanities and social sciences for universities, Sichuan year 0-3 early childhood development and education research center project "mode and curriculum research of on-the-job teacher training in early childhood 0-3 years old" (SCLS15-017).

\section{References}

[1] X.F. Qin: Studies in Preschool Education, (2011) No. 10, p. 28.

[2] Z.J. Deng and L. Guo: Education and Teaching Research, Vol. 27 (2013) No.11, p.114.

[3] W. Cai: Study on the Survival Status of Private Kindergarten Teachers in Henan (MS., Henan University, China 2010), p.7.

[4] L.J. Zhang, W. Zhang and L.L. Zhang: Modern communication, (2011) No.10, p.156.

[5] T. F. A. Taleb: Early Childhood Education Journal, Vol. 41(2013) No.2, p.143. 
[6] X.J. Xiao and X. Han: Labor in China, (2015) No.6, p.38.

[7] J.Y. Li: Investigation and Study on the Living state of Kindergarten Teachers in Dalian (MS., Liaoning Normal University, China 2008), p.5.

[8] H.Y. Tang: Study on the Survival Status of Rural Private Kindergarten Teachers in Rudong County (MS., Nanjing Normal University, China 2007), p.16.

[9] Y.Y. Xie and Z.J. Liu: Contemporary educational theory and Practice, Vol. 8(2016) No.7, p.148.

[10]A.H. Hua: Apocalypse of Preschool Education Reform (Shanghai Academy of Social Sciences Press, China 2009), P.175.

[11]X.M. Wang: Journal of Hubei Correspondence University, (2017) No.21, p.92.

[12]Y.P. Xia, S.H. Liu and L. Zhang: Journal of Gansu Normal Colleges, Vol. 19 (2014) No.2, p.123. 